\title{
Research on the Current Situation and Problems of Higher Education in China under the New Situation
}

\author{
Shi Lei \\ Teaching and research section of Information management, \\ Information and Technology College, Jilin Agricultural \\ University \\ Changchun, China \\ shil0212@sina.com
}

\author{
$\mathrm{Su} \mathrm{Yi}$ \\ Fuxin animal disease prevention and control center \\ Fuxin, china \\ 419998007@qq.com
}

\begin{abstract}
In today's economic globalization, higher education has become an important factor affecting the national economic development and improving the quality of the people. It is particularly important to develop higher education. Through the research, it is found that there are some unreasonable phenomena in Higher Education in China, such as the quality of education and teaching, the allocation of resources and input. In this paper, the methods of literature and analysis are used to analyze the problems in China's higher education, and to analyze the current situation and problems in the development of higher education in China in detail through the support of specific data. Finally, this paper puts forward that the higher education in our country will emphasize the quality of education and the rational allocation of resources in the future, which will make the education more targeted and more reasonable.
\end{abstract}

Keywords-Higher education; Development Status; Present situation; Development problem

\section{INTRODUCTION}

Since the reform and opening to the outside world, China's higher education [1-2] has made remarkable achievements and formed a higher education system that meets the needs of China's national economic construction and social development. Higher education is an important part of China's education. As of May 30, 2016, there were 2879 institutions of higher learning in china [3-4]. Although the scale of colleges and universities in our country is expanding, there are still many problems to be solved. "Elite and popular education" is the inevitable trend of China's educational system reform and development. According to our national conditions, our country's higher education will be a trend of coexistence of "popular education" and "elite education" in the coming period [5].

Since the middle of $1990 \mathrm{~s}$, our country has adopted the strategy of invigorating the country through science and education and talents, and has made new adjustments to the reform and development of higher education[6-7]. During this period, there were successful experiences and valuable lessons to be learned, but now it is time to sum up these experiences and lessons, through the summary of experience and lessons in the process of development, we should further promote the healthy and sustainable development of higher education, and promote the development of China's economy and the promotion of international status.

This article mainly adopts the method of literature and comparative analysis, analyzing the current situation of higher education development and the factors influencing the development of higher education in china, Combined with foreign advanced school running concept, combining foreign advanced educational concepts, putting forward the development of China's higher education which need to solve, exploring the development trend and reform trend of China's higher education in the future [8-10].

\section{CURRENT SITUATION AND EXISTING PROBLEMS OF HIGHER EDUCATION DEVELOPMENT}

With the rapid development of economy and the deepening of reform, the scale and quality of higher education in China are gradually improved; higher education in our country is in the development stage of popular education mode, however, influenced by the population base, there is still a big gap between China's higher education per capita educational investment and other developing countries, and even cannot catch up with the higher education in some low-income countries, therefore, China's higher education will be faced with many problems, such as not to explore and put forward corresponding countermeasures, which will hinder the internationalization of China's higher education.

\section{A. The scale of colleges and universities develops too fast}

The state has substantially increased the enrollment of institutions of higher learning. Fig. 1 shows the changes in the scale of higher education students in China from 2008 to 2015. In 2015, the gross enrollment rate of higher education in China reached $40 \%$. In a few short years, the scale of China's higher education development has become the first in the world. 


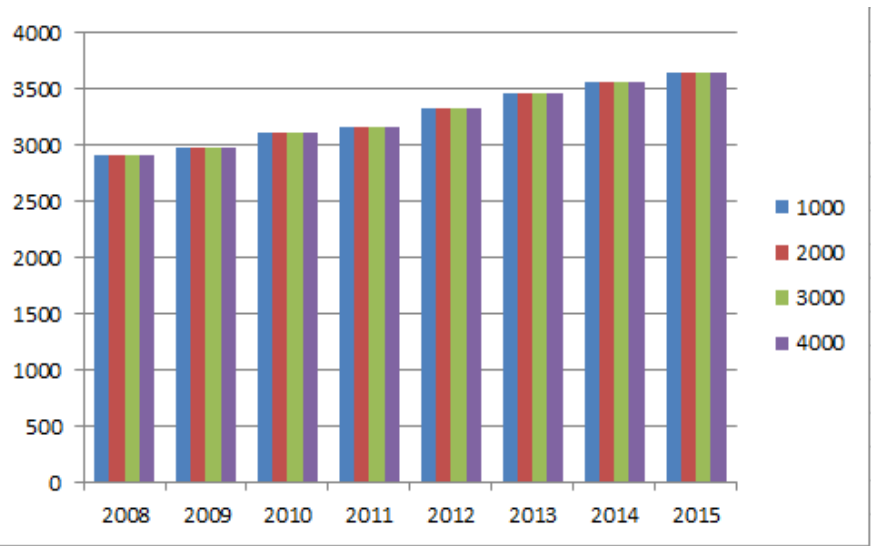

Fig. 1. 2008-2015 Total scale of students in Higher Education

Elite education pays more attention to the construction of teaching staff and teaching quality, with the expansion of the scale of universities and the increase of the number of students, the quality of teachers is insufficient and the quality of teaching is decreasing. With the deepening of China's population aging, the deepening of reform and opening up, Society needs more professional talents, and the construction of teaching quality is more important at the present stage, which will directly affect the economic development of our country.

\section{B. Unbalanced development of Higher Education}

The uneven distribution of educational resources in China mainly reflects the geographical aspects, but also including investment in economy, teachers and teaching resources.

\section{1) The development of teaching staff and teaching} resources is uneven.

The imbalance between teachers and teaching resources in China is mainly between the eastern, central and western three regions, There are 985 Colleges 39, 211 Engineering Colleges 112, key universities of China are mainly distributed in the eastern coastal area from fig.2. The main reason is the economically developed eastern regions, national policy support, so more adequate educational resources. The distribution of educational resources in Central China is relatively balanced, and education can basically be satisfied. In the western part of China, the economy is backward, and the educational resources are seriously insufficient, and the educational conditions are bad, which seriously affects the level and degree of people's education.

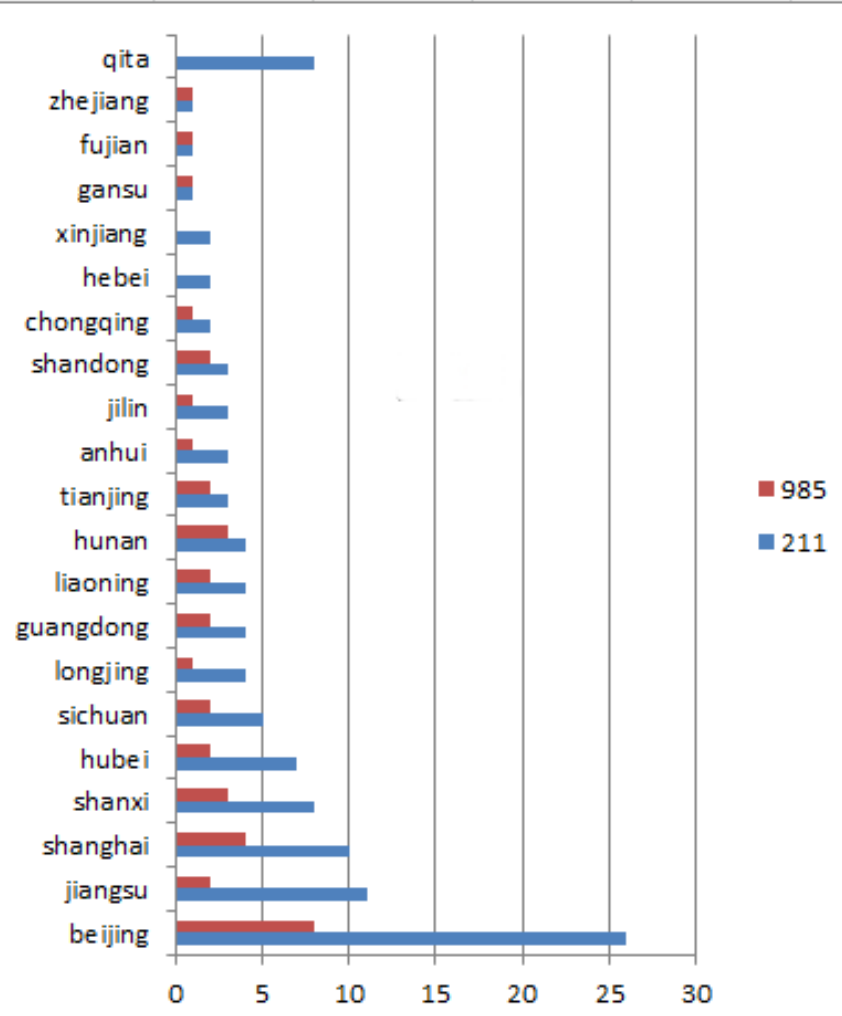

Fig. 2. Number of universities 985 and 211 in provinces

\section{2) For Economic input imbalance.}

We will divide the local higher education area into three regions, which are developed in the eastern region including Beijing, Tianjin, Shanghai, Hebei, Jiangsu, Liaoning, Fujian, Guangdong, Shandong, Zhejiang, Hainan, Guangxi. The middle developed areas include Jilin, Shanxi, Anhui, Heilongjiang, Henan, Inner Mongolia, Hunan, Hubei and Jiangxi. The west is a relatively backward region, including Chongqing, Sichuan, Guizhou, Gansu, Shaanxi, Tibet, Qinghai, Ningxia, Yunnan, Xinjiang. Due to the disparity of economic development in the East, middle and west regions, there is a gap in the financial input of our government's higher education. Investment in Higher Education in 2014 is fig.3. Investment in Higher Education in China from 2012 to 1016 is fig.4. 


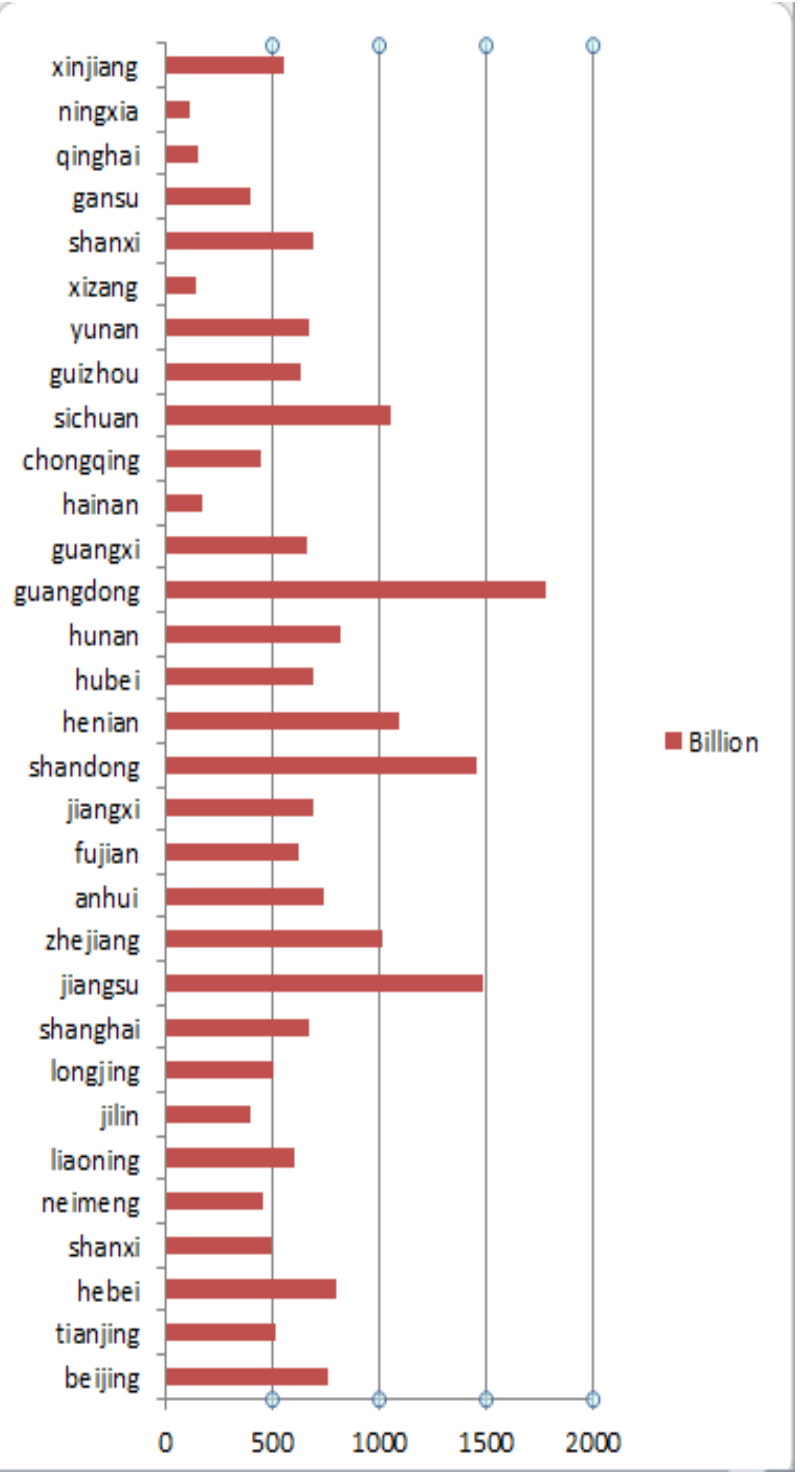

Fig. 3. invested in Higher Education in all provinces in 2014

\section{The financial expenditure is limited}

The financial allocation of higher education in China and the United States is basically the same. In recent years, the investment in Higher Education in China has been increasing. Influenced by the development of economy and population, the expenditure of educational expenditure in every module of our country needs great expense, comparing with the developed countries such as the United States, the expenditure of higher education in China still has a big gap, and even cannot reach the level of some low-income countries.

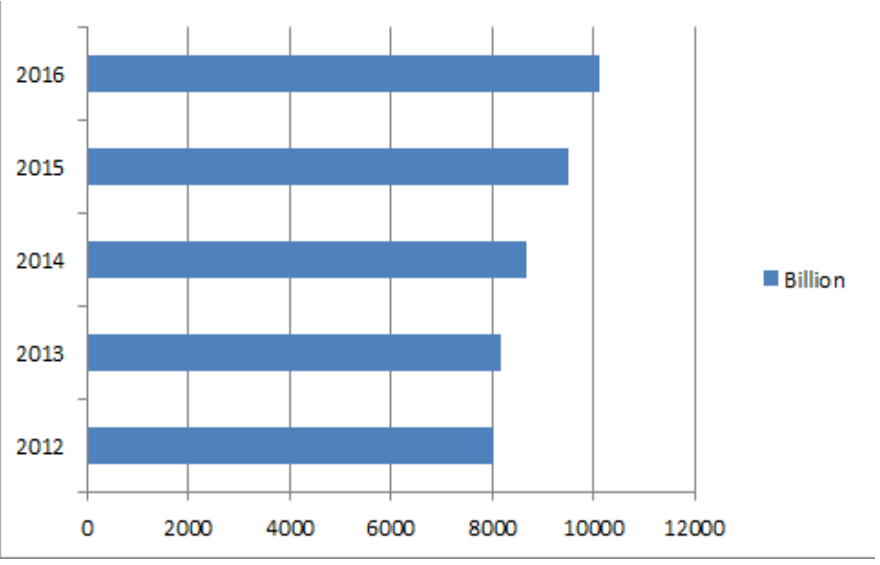

Fig. 4. Investment in Higher Education in China from 2012 to 1016

\section{Difficult employment for College Students}

College students are the backbone of China's construction and development, and their employment has a far-reaching impact on China's social and economic development. Employment difficulties are mainly reflected in the following aspects: With the expansion of college enrollment, the number of college graduates has been on the rise, and the number of college graduates is huge; The good and bad university graduates' cultural accomplishment and the students' expectation of employment are too high, not objective and not calm; Poor practical ability, resulting in social college students are mostly " Have degrees, No level; Have educational background, No ability" phenomenon; Without understanding the society, not objectively or calmly looking for the right job, not actively adapting to the needs of society.

\section{COPING STRATEGIES}

\section{A. Optimize the idea of running a school and make clear the characteristics of running a school}

The idea is action oriented, the concept is the starting point and end point of a school, advanced education philosophy can help universities to improve the teaching level and scientific research strength. We should make clear the idea of running a school, make clear the purpose and the goal of running a school, and lead the development of the school with the advanced idea of running a school. The characteristic is the brand, we should make great efforts to create the different region, different university school running characteristic, realizes the discipline intersection, the specialized intersection.

\section{B. Rational allocation of teaching resources}

We should vigorously promote education equity, gradually narrow the gap, and allocate educational resources fairly; we should speed up the development of education in the central and Western regions; we should expand the efforts to optimize the Weak Universities and tilt the funds; Enlarge the enrollment scale in backward areas of education development; we should expand the efforts to optimize the Weak Universities and tilt the funds; Realizing the rational distribution of educational resources. 
1) Improve the allocation of higher education resources by the government.

Under the current management system of our country, the financial appropriation of higher education funds incline to the less developed areas of middle and Western China, and relieve the financial pressure of local government; In the less developed areas, expanding the number of key colleges and universities, so that more students have access to higher education; improving the employment mechanism so as to retain talents in less developed areas; supporting or building key institutions in less developed areas.

2) Colleges and universities optimize their allocation of resources by themselves.

Institutions of higher learning must formulate their own strategic plans and directions for their own development, optimize the allocation of resources, and strive for maximum benefits; all kinds of resources on campus are shared, and the strengths of each department are brought into play so as to maximize the advantages and utilization of resources.

\section{College students, employment, countermeasures}

First of all, we should guide graduates to actively adjust their employment expectations, change the traditional employment thinking, such as large state-owned enterprises, institutions, civil servants, and set up the correct idea of employment and make a scientific and suitable job objective, make reasonable plans for your career, find your strengths, and find your weaknesses. We should guide students to take the professional knowledge as their point of employment and enhance their comprehensive quality.

\section{CONCLUSION}

In today's economic globalization, higher education has become an important factor affecting the development of the national economy and improving the quality of the people, therefore, it is of great significance to study the current situation and problems of higher education development, This paper analyzes the development status of China's higher education, found that the current higher education in our country has the scale of development is too fast, the funding problem is not reasonable, teachers and teaching resources in areas such as the uneven distribution. In view of these problems, the corresponding countermeasures are put forward.

\section{REFERENCES}

[1] People's Republic of China National Bureau of statistics, China Statistical Yearbook 2016. Beijing: China Statistics Press, 2016. (In Chinese)

[2] ChenChen, KangMin, XieQing, Liling Lin, RaoPei, "The development trend of higher education in the era of big data," in MEITAN HIGHE R EDUCATION.2015, vol. 3, pp.39-43. (In Chinese)

[3] ZhuXu, "The trend of regionalization of Higher Education," in Chinese Market, 2016, vol.14, pp.86-92. (In Chinese)

[4] LiWei, LuFeng, "R esearch Characteristics and Developing Trend in International Distance Education," in Journal of R adio \& TV University( Philosophy \& Social Sciences), 2016, vol.4, pp.96-104. (In Chinese)

[5] Xuanzuo Lin, Haiyan Zhong, "Talking about the present situation and development trend of Higher Education," in Bridge of Century, 2015, vol.4, pp.61-63. (In Chinese)

[6] Xiaojing Guo, "Research on the development trend of Higher Education under the background of informatization," in Bridge of Century, 2017, vol.1, pp.129-131. (In Chinese)

[7] Hongbing $\mathrm{Hu}$, "Research on the irrational allocation of higher education resources in China," in Theory Research, 2014, vol.17, pp.161-163. (In Chinese)

[8] LiuChang, "College Students' employment difficulties and Countermeasures," in Times education, 2013, vol.3, pp.45-45. (In Chinese)

[9] XuChuang, Ziyang Zhang, Taiyu Shen.. "Research on Current Situation of the Development of Network Teaching," in Animal Husbandry and Feed Science, 2016, vol.37, pp.55-56. (In Chinese)

[10] Dayun Chen, "The direction, Core, path of higher education development under the new situation in China," in Xuexiao Dangjian Yu Sixiang Jiaoyu, 2017, vol.1, pp.57-59.(In Chinese) 